\title{
Care pathways for dementia: current perspectives
}

\author{
Kritika Samsi \\ jill Manthorpe \\ Social Care Workforce Research Unit, \\ King's College London, London, UK
}

Correspondence: Kritika Samsi Social Care Workforce Research Unit, King's College London, 2nd floor, Virginia Woolf Building, 22 Kingsway, London WC2R 2LS, UK

Tel +44207848I665

Fax +44 207848 I866

Email kritika.I.samsi@kcl.ac.uk
This article was published in the following Dove Press journal:

Clinical Interventions in Aging

27 November 2014

Number of times this article has been viewed

Abstract: Uncertainty appears to typify the experience of living with dementia. With an uncertain illness trajectory and unpredictable levels of deterioration and stability in symptoms, people with a diagnosis of dementia may live with uncertainty and anxiety and find it hard to make plans or decisions for their future. People with memory problems and caregivers seeking a diagnosis of dementia may also potentially find themselves navigating a labyrinth-like maze of services, practitioners, assessments, and memory tests, with limited understanding of test scores and little information about what support is available. In this context of uncertainty, the apparent clarity and certainty of a "dementia care pathway" may be attractive. However, the term "dementia care pathway" has multiple and overlapping meanings, which can potentially give rise to further confusion if these are ill-defined or a false consensus is presumed. This review distinguishes four meanings: 1) a mechanism for the management and containment of uncertainty and confusion, useful for the professional as well as the person with dementia; 2) a manual for sequencing care activities; 3 ) a guide to consumers, indicating eligibility for care activities, or a guide to self-management for dementia dyads, indicating the appropriateness of care activities; and 4) a manual for "walking with" the person. Examples of these approaches are presented from UK dementia services with illustrations of existing care pathways and associated time points, specifically focusing on: 1) early symptom identification and first service encounters, 2) assessment process, 3) diagnostic disclosure, 4) postdiagnostic support, and 5) appropriate interventions. We review the evidence around these themes, as well as discuss service pathways and referral routes used by some services in England and internationally. We conclude that the attraction of the term "care pathway" is seductive, but caution is needed in taking shared understandings for granted.

Keywords: dementia, care pathways, diagnosis, assessment

\section{Introduction}

\section{Dementia as a global concern - are pathways the solution?}

The growing numbers of people with dementia worldwide have recently attracted global interest - the World Alzheimer Report 2009 predicted worldwide estimates of 36 million people living with dementia in 2010, doubling every 20 years to 66 million by 2030 and to 115 million by $2050 .{ }^{1}$ New age-specific data from Asia East (People's Republic of China) and Sub-Saharan Africa predict increases of 15\% in 2030 (to 75.62 million) and of $17 \%$ in 2050 (to 135.46 million people). ${ }^{2}$

In 2010, the total worldwide costs of dementia were estimated to be US \$64 billion, with $70 \%$ of these costs occurring in Western Europe and North America, ${ }^{3}$ and containing these costs is also seen as a policy imperative. As a consequence of these two trends, governments have expressed their commitment to sharing systematic approaches for preventing, diagnosing, and treating dementia and have developed national plans to achieve nationally specific aims. ${ }^{4}$ At the international level, a World Dementia Council was launched in 2014 following the G8 summit in 2013 in London, UK. 
National dementia plans or strategies generally detail ambitions to promote timely identification and to provide effective interventions and support for people with dementia and their caregivers. Enabling and improving access to diagnosis and support appear in the national plans of Australia, England, France, the Netherlands, and Canada (albeit with varying emphases), while those of Norway, USA, Finland, and Republic of Korea discuss clarifying existing pathways and referral routes. Shared policy goals include removing barriers to access and establishing clear care pathways and referral routes.

\section{Does the "dementia journey" need a pathway?}

Living with dementia is often reported as being beset with confusion and anxiety, from when individuals or family members begin to get worried about their memory problems or difficulties managing daily life, and then deciding to seek help for this. ${ }^{5,6}$ The condition itself is typified by uncertainty, an unclear disease trajectory, and lack of clarity about symptoms. In the current context of encouraging individuals to set out advance care plans and to be explicit about their health and care preferences, many people with dementia and their family members, may appreciate a clearer picture of the prognosis and timelines to know when to make plans or when care and support need to be increased. The term "care pathway" may offer the promise of reassurance but, as the following sections show, there are many constructions of this term.

\section{Care or critical pathways}

The term "dementia care pathway" has multiple and overlapping meanings. This review distinguishes four meanings: 1) a mechanism for the management and containment of uncertainty and confusion, useful for the professional as well as the person with dementia; 2) a manual for sequencing care activities; 3 ) a guide to consumers, indicating eligibility for care activities, or a guide to self-management for dementia dyads (person with dementia and their caregiver), indicating the appropriateness of care activities; and 4) a manual for "walking with" the person. Examples of these approaches are presented from UK dementia services. We will argue that the attraction of the term "care pathway" is increasingly evident but caution is needed in taking shared understandings for granted.

Over the last 30 years, the idea of a critical or care pathway has been used in different health settings. The terms care pathway, critical care pathway, clinical pathway, integrated care pathway (ICP), or care map may suggest slightly different approaches, but overall they may be used (interchangeably) to systematically plan patient care, to modify or vary it, and organize follow-up. Schrijvers et al ${ }^{7}$ have recently provided a helpful background to the development of care pathways, defining them in the context of the Netherlands as being "process innovations that focus on improving the organization of care processes." Such definitions are helpful in pointing to the many possible interpretations of the purpose and possible beneficiaries of a pathway approach or system.

The authoritative European Pathway Association defines a care pathway as "a complex intervention for the mutual decision making and organization of care processes for a well-defined group of patients during a well-defined period" (Table 1). ${ }^{8}$ Table 1 contains a recent compilation of the characteristics of a care pathway. In this review we use the term care pathway as a general term, except when another term has been used in a document we use the original term. More recently, the term "integrated care pathway" has been employed. One definition of this is as "a multidisciplinary outline of anticipated care, placed in an appropriate timeframe, to help a patient with a specific condition or set of symptoms move progressively through a clinical experience to positive outcomes."

Table I Definition of care pathway from the European Pathway Association

"Defining characteristics of care pathways include:

(i) An explicit statement of the goals and key elements of care based on evidence, best practice, and patients' expectations and their characteristics;

(ii) The facilitation of the communication among the team members and with patients and families;

(iii) The coordination of the care process by coordinating the roles and sequencing the activities of the multidisciplinary care team, patients and their relatives;

(iv) The documentation, monitoring, and evaluation of variances and outcomes; and

(v) The identification of the appropriate resources.

The aim of a care pathway is to enhance the quality of care across the continuum by improving risk-adjusted patient outcomes, promoting patient safety, increasing patient satisfaction, and optimizing the use of resources."

Notes: Copyright (C) 2010. Reproduced from Vanhaecht K, Panella M, Van Zelm R, Sermeus W. An overview on the history and concept of care pathways as complex interventions. International Journal of Care Pathways. 2010;14(3):1 17-123. ${ }^{8}$ 
However, as Schrijvers et $\mathrm{al}^{7}$ observed, “[...]care pathways are per definition integrated. Fragmented care pathways cannot exist."

\section{Care pathways in dementia}

Care pathways in dementia can refer to a patient's route into services and choices of support and treatment. Metaphors such as "journey", "roadmap", and "labyrinth", and associated images such as encountering "barriers and facilitators" and "signposts" along this path, are commonly used in research presenting patient experiences. Unsurprisingly, the impression of clarity and certainty as suggested by a pathway is attractive to patients.

However, a care pathway in dementia is not straightforward. Most health systems and health and care facilities determine their own service criteria, and even the referral routes to specialist care may vary considerably. Person-centered care and professional discretion, the guiding principles of good quality dementia care, complicate the suggestion of a care pathway as a unified approach. In particular, individuals are likely to prefer different approaches to how they are assessed, referred, and diagnosed, ${ }^{10}$ and they often have many other long-term conditions which impact on what they do and think about dementia symptoms.

Globally, national dementia strategies have routinely stressed the importance of clear dementia pathways to support patients and caregivers as they seek a diagnosis of dementia. ${ }^{11}$ However, there are some important differences between countries with regards to the emphasis placed on different stages of the care pathway. For instance, while the English strategy prioritizes timely diagnosis and reducing stigma, the Australian focus is on strengthening primary care and counseling support for people with dementia. ${ }^{12}$ Most of the steps in documentation or systems that are called care pathways seem to have been developed as guides for clinicians in primary and secondary care sectors to set out the "rules" for when to investigate further and at what step to refer for specialist care. These care pathways may be shared with potential patients in order to help them understand the assessment and diagnostic process. They may also be an effective way of organizing billing or reimbursement systems, and patient involvement here may be limited.

One further development in dementia and other mental health services has been the ICP. This implies going beyond health services to cover other agencies supporting people with dementia. In Scotland, for example, the ICP mentions local government, and not-for-profit and profit-making services, as well as health services (Healthcare Improvement Scotland) (Table 2). ${ }^{13}$

A further and important development in the UK has been the controversy over one particular care pathway, which had great relevance to people with dementia and their caregivers. An independent review of the Liverpool Care Pathway for the Dying Patient, entitled "More Care, Less Pathway", was commissioned following media and political concern that this ICP was sometimes used as a "tick box exercise," and care of the dying patient and their caregivers was poor. ${ }^{14}$ The review found that many families felt relatives' deaths had been quickened by unnecessary, "premature or overprescription of strong pain killing drugs or sedatives", often "without discussion or consultation".

The Liverpool Care Pathway was phased out, and at July 2014 it no longer exists.

\section{Time points along dementia care pathways}

There appear to be similar time points along most dementia care pathways, although there are some key differences. The dementia care pathway developed in England by the National Institute of Health and Clinical Excellence (NICE) has as its starting point "training staff" using "principles of care" and touches on "risk factors and prevention." The NICE

Table 2 What an ICP for dementia should do

"Recognize the individuality and capabilities of each service user and ensure that they are treated with dignity and respect

Help the person with dementia understand and manage their illness and enhance their strengths (things they can still do)

Help informal caregivers to continue caring for as long as practical

Have a rehabilitative emphasis to help people with dementia have the best quality of life possible within the limitations of their illness

Be understandable to people with dementia and their informal caregivers, and

Be consistent with the principles of the Adults with Incapacity (Scotland) Act 2000, ie, decisions made on behalf of an adult with incapacity must: benefit the adult, take account of the adult's wishes as far as they can be ascertained, take account of the views of relevant others, as far as is reasonable and practicable to do so, restrict the adult's freedom as little as possible while still achieving the desired benefit and encourage the adult to use existing skills and develop new skills."

Notes: Copyright (C) 2014 Healthcare Improvement Scotland. Reproduced from Integrated care pathways for mental health [webpage on the internet]. Healthcare Improvement Scotland. Available from: http://www.icptoolkit.org/condition-specific_care/dementia.aspx. Accessed October I4, 20I4. ${ }^{13}$ Abbreviation: ICP, integrated care pathway. 
pathway ${ }^{15}$ is therefore a more holistic guide for practitioners to consult when developing or offering services for people with possible dementia but also extends to professional training and the difficult matter of prevention. The NICE pathway also encourages postdiagnostic support such as promoting choice, maintaining independence, and supporting caregivers. The National Health Service (NHS) Choices Map of Medicine ${ }^{16}$ developed in England is designed to be more "user-friendly" or easier for patients to understand. It too provides a "map" of when it considers that specialist care may be beneficial and when a referral is likely to be appropriate in the NHS context. This might be seen as a form of guided consumerism with messages about eligibility and expectations within it. In England the Social Care Institute of Excellence's ICP includes end-of-life care as the final stage at which a person with dementia needs services, but takes the pathway one step further by noting that services may provide care for family caregivers to be supported beyond the death of their relative with dementia. Similarly, the Dementia Services Pathway produced by the Australian government ${ }^{17}$ also includes end-of-life care in dementia, thereby depicting the care pathway not just as a route into services, but as a pathway throughout life with dementia.

Taken together, the main points along a dementia care pathway from an individual perspective have been constructed as a linear route along services for a person seeking a diagnosis for their memory problems or similar difficulties and as an aid to clinicians. In an uncertain condition, the aim appears to be greater clarity for all. After all, there is wide variation in presenting symptoms of dementia, there is limited value of memory loss as an indicator of dementia, there are poor correlations between pathological changes in the brain and behavior, there is difficulty in separating depression and dementia at the beginning, and there is much variation in life expectancy following diagnosis. Moreover, the noun pathway suggests a more "friendly" term than conveyer belt with all that this implies about an impersonal or industrial model of care. There is little evidence about the perceptions of clinicians of the term and the changes that using the term "pathway" may make in professional interactions with patients. Rooney has recently observed that "Pathways are generally based on the evidence base developed from research, but despite this, they do not enjoy immediate universal uptake. The translation of research to clinical practice has formed the basis of the relatively new discipline of implementation science". ${ }^{18}$

An ideal dementia care pathway is described as iterative, with repeated assessment and reviews as the condition and needs of the individual change over time. ${ }^{19}$ Such a model suggests that a variety of health and social care professionals will be involved, from diagnosis to end-of-life care, possibly with the primary care physician being in the central role of coordinator of this care. ${ }^{19}$

Our review found numerous examples of the word "pathway" being used to describe several different activities. For example, in a recent strategic document outlining nurses' roles in dementia in England the term "pathway" is used to describe the many levels that a nurse might be working at and the skills they might need. ${ }^{20}$ Caution is therefore also needed in seeing a "pathway" as agreed between professionals.

A lack of research evidence about the actual experiences of pathways means that we do not know how the idealized version of a care pathway is followed in practice or its outcomes, but understanding the points along this pathway may be a helpful analytical tool. For the purpose of this review, we outline four common points along dementia care pathways and the evidence behind them:

1. Early symptom identification and first service encounters

2. Assessment process

3. Diagnostic disclosure

4. Postdiagnostic support and appropriate interventions.

\section{Early symptom identification and first service encounters}

The global drive to timely identification and assessment of memory problems has led to widespread campaigns to raise the awareness of early symptoms to encourage people to seek help, the value of which was recently debated. ${ }^{21}$ Persistent barriers, however, still remain because early referral rates are still low and many people with dementia live without ever receiving a formal diagnosis of dementia. Memory problems are the most common reasons cited for people seeking help themselves, ${ }^{6,10,22-26}$ although trigger events can also often be emergency care, hospitalization, or bereavement. ${ }^{27-32}$ The most common barriers to help-seeking have been reported to be lack of awareness, combined with pervasive cultural attitudes, and attributing symptoms to aging not warranting further investigation. . $^{3,26,33}$

Most people's first point of call when seeking help is unsurprisingly their primary care physician. Studies have found that for multiple reasons doctors can be slow or reluctant to refer for specialist care, ${ }^{34,35}$ although not all have found this to be the case. ${ }^{10}$ Family members can be instrumental in seeking help for a relative with memory problems. ${ }^{3}$ First service encounters seem to be crucial in patients' quests for 
answers and how these are handled can alleviate anxiety and distress among patients worried about their symptoms and among their caregivers.

The NICE dementia pathway is a good illustration of the clinical judgment and decision-making processes around diagnosis and assessments as it contains detail about tests that should be conducted and those that are not to be routinely undertaken. ${ }^{15}$

\section{Assessment process}

A common next step along a dementia care pathway is referral from primary care for more specialist assessment and treatment. The primary care physician or General Practitioner (GP) is acknowledged as having a crucial role to play in facilitating access to this service. ${ }^{6,36}$ As noted, studies have reported that this is not always straightforward, with doctors sometimes reluctant to make a referral to memory services for various reasons. ${ }^{37,38}$ The experience of visiting a memory clinic for assessment can be daunting and frightening. ${ }^{10,28,39,40}$ In England, the Map of Medicine dementia pathway has been designed for primary care, setting out when GPs should make decisions about testing and the next steps when a patient presents with memory problems. In a recent study, most GPs interviewed said they used the Map of Medicine pathway, yet data from the local Pathways Audit showed that many patients were referred without having undergone the steps set out in the Map of Medicine. ${ }^{41}$

Although different aspects of the assessment process have been studied, ${ }^{24,25,29,39,42}$ there continues to be very little understanding of the patient experience of the assessment process and the feelings associated with it. Large reviews have also often missed this crucial aspect ${ }^{3}$ as they tend to focus on early symptom recognition and the impact of the diagnosis and miss the role of the assessment process and the importance of it not promoting problems. We conducted one of the few studies ${ }^{5,10}$ in this area and interviewed people moving from the state of having memory problems to receiving a diagnosis of dementia. Anxiety and confusion typified the entire assessment process, and many talked of it in terms of "entering a labyrinth," with no signs or markers about what would happen when or why. Patients and caregivers were often dogged by long waiting times, and few knew where to turn for further information and advice, a finding replicated in later studies. ${ }^{10,22,43,44}$ Many felt anxious during memory tests and considered that practitioners had done little to reassure them. Few were aware of what outcomes of tests would denote, and scores were meaningless to them. ${ }^{10,39}$ Clarity during this process regarding who they were being assessed by, how long it would take, what the different outcomes might signify may reduce patients' confusion, alleviate anxiety, and help with managing expectations. ${ }^{5}$

One example of an assessment pathway is from a service focusing on the care and support of people with learning disabilities (intellectual impairment). In light of the challenges of supporting people with learning disabilities, some clinicians have developed a pathway for referrals and part of this is designed to ensure appropriate information is gathered to aid the assessment of people with learning disabilities when dementia is suspected. Clinicians are recommended to use this to guide their practice and to document the assessment and diagnosis process. Termed the "Dementia Best Practice Guidelines," the document is described as being part of the Learning Disability and Dementia Memory Assessment Pathway $^{45}$ and is placed on a national web resource by Public Health England.

\section{Diagnostic disclosure or communication}

The manner in which a diagnosis of dementia is communicated to the patient and the support offered at this time may be crucial in how people cope with the condition long-term. ${ }^{10}$ Whether a diagnosis of dementia should be disclosed has been extensively discussed. ${ }^{6}$ Participants in many studies have argued that disclosing the diagnosis is not a one-off event, but a process, with a series of meetings needed to give time for people with memory problems and their caregivers to think of questions and raise concerns. ${ }^{5}$ Conducted sensitively, with previously explored expectations acknowledged and adequately managed, this process may instill confidence in people with dementia and equip them with appropriate coping strategies to manage their symptoms. ${ }^{10} \mathrm{~A}$ discussion of the possibility of dementia before a diagnosis is confirmed may be helpful, so that the news potentially comes as less of a shock. ${ }^{46-48}$

The impact of a diagnosis of dementia has been studied extensively. $3,6,10,24,48,49$ This can be positive, with many experiencing relief and closure to months of speculation and anxiety, ${ }^{50-52}$ and an opportunity to begin to adjust and accommodate change. ${ }^{44,53,54}$ For others, this can be distressing, with feelings of anger, frustration, and denial, and an overwhelming sense of loss. ${ }^{47,48,50,54,55}$ Caregivers of people given a diagnosis have their own feelings to come to terms with. ${ }^{22}$ Reliance on family caregivers may become more important, ${ }^{47}$ as previous roles and relationships may become harder to maintain. ${ }^{44}$ Some people with dementia may become socially isolated as they struggle to accept their diagnosis. ${ }^{26,29,56}$ The role of family caregivers may become more crucial, which 
can have its own adverse consequences on the health and well-being of caregivers. ${ }^{36,57,58}$ Most dementia care pathways, therefore, give equal importance to supporting caregivers of people with dementia. The process of diagnostic disclosure needs to be handled with skill, forthrightness, sensitivity, patience, and a person-centered approach. ${ }^{5,59}$

\section{Postdiagnostic support}

Postdiagnostic support, as described along a dementia care pathway, tends to depend upon the specific diagnosis and the stage of the dementia. There have been concerns that people with mild cognitive impairment (when a diagnosis is not otherwise certain) often receive no support and are simply asked to return in a year's time to a memory service or if symptoms appear to worsen. ${ }^{60}$ Those given a diagnosis of vascular dementia sometimes report being offered no support, if support locally is concentrated around the provision of symptom modification medication. ${ }^{5}$

Acetylcholinesterase inhibitors are the most common type of medication prescribed to alleviate some of the symptoms of Alzheimer's disease. There appears to be growing public expectation that all diagnoses of dementia bring entitlement to medication, potentially resulting in disappointed expectations. ${ }^{5,10,61}$

The use of psychosocial interventions to alleviate some of the symptoms of dementia has grown in popularity in recent years, as new and innovative therapeutic approaches are trialed, including cognitive stimulation therapy and reminiscence therapy, among others. Studies have also found consistently high demand for advice, social networks, and community and peer support. 5,6,36,40,43,52,54,62,63 Information from voluntary or third-sector organizations is also valued. 6,31,38,64,65 These are generally referred to in dementia pathways, which make reference to postdiagnosis support. The Dementia Roadmap, (http://dementiaroadmap.info $)^{66}$ for example, was recently developed in the UK by the Royal College of General Practitioners, as a tool (online platform) to assist primary care staff to support people with dementia and their families. The online platform is designed to include local information and serves as a "one-stop shop" for professionals to consult when referring patients or caregivers to local services, support groups, and networks (Table 3 ). The expectation is for the roadmap to bring together (metaphorically) practitioners, people with dementia, and caregivers and provide a resource for

"understanding dementia, memory worries, the diagnostic process, post-diagnosis support, living well with dementia, carer (caregiver) health and planning for the future." ${ }^{\circ 7}$

Although multidisciplinary teams are variable in their arrangements in the UK, the roadmap is intended to encourage integrated working between practitioners through better information sharing and delegation of powers to other social services and providers. ${ }^{68}$ At the time of writing (July 2014), four regions in England have developed Dementia Roadmaps. These can be accessed via the Dementia Roadmap platform available from http:// dementiaroadmap.info that also cites potential advantages to the availability of this resource (Table 3 ). ${ }^{66}$

\section{Conclusion}

This overview of dementia care pathways has highlighted the multiple meanings of pathways and ways in which the term is being used to describe system connections and the content

Table 3 Ambitions for local dementia roadmaps (Dementia Roadmap)

- Introduce questions about memory functioning in scheduled visits and routine health checks and investigations for people identified as potentially at risk.

- Assess and identify patients who present with symptoms suggestive of dementia. "Signposting" (referring or telling them about) patients to relevant resources or services.

- Reassure patients and their carers/families at diagnosis and during the dementia journey by signposting them to local resources, information, and support.

- Promote positive messages about remaining independent and living with dementia. This can help to prevent unnecessary admission to hospital for patients with memory problems in crisis.

- Provide support for carers (caregivers) to maintain their health and well-being and provide opportunities for respite for the person they care for (local information about respite availability and criteria).

- Support patients more efficiently, thereby reducing multiple/repeat appointments.

- Refer patients to specialist services where appropriate.

- Keep accurate records, coding patients who present with memory problems appropriately.

- Use case finding approaches with colleagues to identify patients with cognitive decline on the (GP) practice register.

Notes: Copyright @ 2014 Dementia Roadmap. Reproduced from Dementia Roadmap [webpage on the Internet]. Available from: http://dementiaroadmap.info. Accessed October 14, 2014. ${ }^{66}$

Abbreviation: GP, General Practitioner. 
of treatment or assessment. For researchers there is a need to carefully describe the content, purpose, and understandings of a pathway as well as considering its possible impacts. The example of the Liverpool Care Pathway in the UK may serve as a reminder that being "under a pathway" may not be welcome and may be perceived by patients and caregivers with some concern. This review of care pathways suggests the risk of seeing them as presenting clarity in an otherwise labyrinth-like system or that there is a linear route into services. Overall, the notion of a pathway appears to be so enticing because patients, caregivers, and professionals themselves may be unaware of what to expect, when and from whom, or simply what to do. Waiting and watchfulness appears to be common for all those who encounter people with symptoms of dementia or who experience such symptoms, again with little certainty about timescales of prognosis or support, and so a pathway may offer hope that there is and will be clarity and continuity of care.

Implementation questions about pathways remain, as well as fundamental questions about their suitability for people who are likely to be frail. For people with dementia with multimorbidity, there is a further complication of being under several possible pathways. This review suggests the importance of locating pathways in the wider system context and explaining them as "ideal" sets of rules or navigation aids, which then need to be negotiated and modified. In the UK context the links between pathway adherence and reimbursement are not well developed, and these may be the next step of pathway development in dementia care.

There remains a need for more research in this area, because although studies have explored the different stages of dementia and how patients and caregivers experience these, robust evidence of the outcomes of care pathways as a whole and the effectiveness of these is required.

\section{Disclosure}

This review was conducted as part of Social Care Workforce Research Unit program of work for the Department of Health Policy Research Programme, England. However, the views expressed in this article are those of the authors and not necessarily those of the Department of Health. The authors have no known conflicts of interest in this work.

\section{References}

1. Alzheimer's Disease International. World Alzheimer Report 2009. London: Alzheimer's Disease International; 2009. Available from: http:// www.alz.co.uk/research/files/WorldAlzheimerReport.pdf. Accessed October 14, 2014.
2. Alzheimer's Disease International. Policy Brief for Heads of Government: The Global Impact of Dementia 2013-2050. London: Alzheimer's Disease International, 2013. Available from: http:// www.alz.co.uk/research/GlobalImpactDementia2013.pdf. Accessed October 14, 2014.

3. Bunn F, Goodman C, Sworn K, et al. Psychosocial factors that shape patient and carer experiences of dementia diagnosis and treatment: a systematic review of qualitative studies. PLoS Med. 2012;9(10): e1001331.

4. Alzheimer's Disease International. National Alzheimer and Dementia Plans Planned Policies and Activities. London: Alzheimer's Disease International; 2012. Available from: http://www.alz.co.uk/sites/default/ files/national-alzheimer-and-dementia-plans.pdf. Accessed October 14, 2014.

5. Manthorpe J, Samsi K, Campbell S, et al. From forgetfulness to dementia: clinical and commissioning implications of diagnostic experiences. Br J Gen Pract. 2013;63(606):e69-e75.

6. Robinson L, Gemski A, Abley C, et al. The transition to dementia individual and family experiences of receiving a diagnosis: a review. Int Psychogeriatr. 2011;23(7):1026-1043.

7. Schrijvers G, van Hoorn A, Huiskes N. The care pathway concept: concepts and theories: an introduction. International Journal of Integrated Care. 2012;[S.1.], September 2012. ISSN 1568-4156. Available from: http://www.ijic.org/index.php/ijic/article/view/812/1894. Accessed October 14, 2014.

8. Vanhaecht K, Panella M, Van Zelm R, Sermeus W. An overview on the history and concept of care pathways as complex interventions. International Journal of Care Pathways. 2010;14(3):117-123.

9. Middleton S, Barnett J, Reeves D. What is an integrated care pathway? Bandolier. 2001;3:3.

10. Samsi K, Abley C, Campbell S, et al. Negotiating a labyrinth: experiences of assessment and diagnostic journey in cognitive impairment and dementia. Int J Geriatr Psychiatry. 2014;29(1):58-67.

11. Government Alzheimer Plans. [webpage on the Internet]. Available from: http://www.alz.co.uk/alzheimer-plans. Accessed July 25, 2014.

12. Brodaty H, Cumming R. Dementia services in Australia. Int J Geriatr Psychiatry. 2010;25(9):887-995.

13. Integrated care pathways for mental health [webpage on the internet]. Healthcare Improvement Scotland. Available from: http://www. icptoolkit.org/condition-specific_care/dementia.aspx. Accessed October 14, 2014.

14. Neuberger J, Guthrie C, Aaronovitch D, Hameed K, Bonser T, Lord Harries of Pentregarth, et al. More care, less pathway: a review of the Liverpool Care Pathway; 2011 Available from: https://www.gov.uk/ government/uploads/system/uploads/attachment_data/file/212450/ Liverpool_Care_Pathway.pdf. 2011. Accessed October 14, 2014.

15. National Institute of Clinical Excellence Pathways. [webpage on the Internet]. Available from: http://pathways.nice.org.uk/pathways/ dementia. Accessed October 14, 2014.

16. NHS Choices Map of Medicine. [webpage on the Internet]. Available from: http://healthguides.mapofmedicine.com/choices/map/dementia1. html. Accessed May 25, 2014.

17. Abbey J, Palk E, Carlson L, Parker D. Clinical Practice Guidelines and Care Pathways for People with Dementia Living in the Community. Brisbane: Queensland University of Technology; 2008.

18. Rooney E. Developing care pathways - lessons from the Steele review implementation in England. Gerodontology. 2014;31(s1):52-59.

19. Matrix Evidence. Spotlight on Dementia Care: Health Foundation Improvement Report. London: Health Foundation; 2011.

20. Department of Health. Making a Difference in Dementia: Nursing Vision and Strategy; 2013. Available from: https://www.gov.uk/ government/uploads/system/uploads/attachment_data/file/147956/ Making_a_Difference_in_Dementia_Nursing_Vision_and_Strategy. pdf. Accessed October 14, 2014.

21. Le Couteur DG, Doust J, Creasey H, Brayne C. Political drive to screen for pre-dementia: not evidence based and ignores the harms of diagnosis. BMJ. 2013;347:f5125. 
22. Hinton L, Franz C, Friend J. Pathways to dementia diagnosis: evidence for cross-ethnic differences. Alzheimer Dis Assoc Disord. 2004;18(3): 134-144.

23. Hutchings D, Vanoli A, McKeith I, Brotherton S, McNamee P, Bond J. Good days and bad days: the lived experience and perceived impact of treatment with cholinesterase inhibitors for Alzheimer's disease in the United Kingdom. Dementia. 2010;9(3):409-425.

24. Leung KK, Finlay J, Silvius JL, et al. Pathways to diagnosis: exploring the experiences of problem recognition and obtaining a dementia diagnosis among Anglo-Canadians. Health Soc Care Community. 2011; 19(4):372-381.

25. Chrisp TAC, Tabberer S, Thomas BD, Goddard WA. Dementia early diagnosis: triggers, supports and constraints affecting the decision to engage with the health care system. Aging Ment Health. 2012; 16(5):559-565.

26. Lawrence V, Samsi K, Banerjee S, Morgan C, Murray J. Threat to valued elements of life: the experience of dementia cross three ethnic groups. Gerontologist. 2011;51(1):39-50.

27. Bowes A, Wilkinson H. 'We didn't know it would get that bad': South Asian experiences of dementia and the service response. Health Soc Care Community. 2003;11:387-396.

28. Corner L, Bond J. The impact of the label of mild cognitive impairment on the individual's sense of self. Philos Psychiatry Psychol. 2006; $13: 3-12$

29. Deb S, Hare M, Prior L. Symptoms of dementia among adults with Down's syndrome: a qualitative study. J Intellect Disabil Res. 2007;51: 726-739.

30. Moniz-Cook E, Manthorpe J, Carr I, Gibson G, Vernooij-Dassen M. Facing the future: a qualitative study of older people referred to a memory clinic prior to assessment and diagnosis. Dementia. 2006; 5(3):375-395.

31. Quinn C, Clare L, Pearce A, van Dijkhuizen M. The experience of providing care in the early stages of dementia: an interpretative phenomenological analysis. Aging Ment Health. 2008;12:769-778.

32. Seabrooke V, Milne A. Culture and Care in Dementia: A Study of the Asian Community in North West Kent. London: Mental Health Foundation; 2004.

33. Adamson J. Awareness and understanding of dementia in African/Caribbean and South Asian families. Health Soc Care Community. 2001;9: 391-396.

34. Bamford C, Lamont S, Eccles M, Robinson L, May C, Bond J. Disclosing a diagnosis of dementia: a systematic review. Int $J$ Geriatr Psychiatry. 2004;19:151-169.

35. Holst G, Hallberg IR. Exploring the meaning of everyday life, for those suffering from dementia. Am J Alzheimers Dis Other Demen. 2003;18: 359-365.

36. Bruce DG, Paterson A. Barriers to community support for the dementia carer: a qualitative study. Int J Geriatr Psychiatry. 2000;15:451-457.

37. Downs M, Ariss SMB, Grant E, et al. Family carers' accounts of general practice contacts for their relatives with early signs of dementia. Dementia. 2006;5(3):353-373.

38. Pearce A, Clare L, Pistrang N. Managing sense of self: coping in the early stages of Alzheimer's disease. Dementia. 2002;1(2):173-192.

39. Keady J, Gilliard J. Testing times: the experience of neuropsychological assessment for people with suspected Alzheimer's disease. In: Harris PB, editor. The Person with Alzheimer's Disease: Pathways to Understanding the Experience. Baltimore and London: The Johns Hopkins University Press; 2002:3-28.

40. Mason E, Clare L, Pistrang N. Processes and experiences of mutual support in professionally-led support groups for people with early-stage dementia. Dementia. 2005;4:79-112.

41. Minghella E. Pathways to Dementia Diagnosis: A Review of Services in the South-West of England, NHS South West of England. 2013.

42. Hughes T, Tyler K, Danner D, Carter A. African American caregivers: an exploration of pathways and barriers to a diagnosis of Alzheimer's disease for a family member with dementia. Dementia. 2009;8(1): 95-116.
43. Beattie A, Daker-White G, Gillard J. "How can they tell?" A qualitative study of the views of younger people about their dementia and dementia care services. Health Soc Care Community. 2004;12(4):359-368.

44. Robinson L, Clare L, Evans K. Making sense of dementia and adjusting to loss: psychological reactions to a diagnosis of dementia in couples. Aging Ment Health. 2005;9(4):337-347.

45. Learning disability dementia assessment pathway and good practice guidance. Available from: http:/www.improvinghealthandlives.org. uk/adjustments/?adjustment=213. Accessed October 14, 2014.

46. Derksen E, Vernooij-Dassen M, Gillisen F, Olde-Rickkert V, Scheltens P. The impact of diagnostic disclosure in dementia: a qualitative case analysis. Int Psychogeriatr. 2005;17(2):319-326.

47. Vernooij-Dassen M, Derksen E, Scheltens P, Moniz-Cook E. Receiving a diagnosis of dementia: the experience over time. Dementia. 2006;5(3):397-410.

48. Aminzadeh F, Byszewski A, Molnar FJ, Eisner M. Emotional impact of dementia diagnosis: exploring persons with dementia and caregivers' perspectives. Aging Ment Health. 2007;11(3):281-290.

49. Llado A, Anton-Aguirre S, Villar A, Rami L, Molinuevo JL. Psychological impact of the diagnosis of Alzheimer's disease. Neurologia. 2008;23(5):294-298.

50. Byszewski AM, Molnar FJ, Aminzadeh F, Eisner M, Gardezi F, Bassett R. Dementia diagnosis disclosure: a study of patient and caregiver perspectives. Alzheimer Dis Assoc Disord. 2007;21(2):107-114.

51. Connell CM, Boise L, Stuckey JC, Holmes SB, Hudson ML. Attitudes toward the diagnosis and disclosure of dementia among family caregivers and primary care physicians. Gerontologist. 2004;44(4):500-507.

52. Werezak L, Stewart N. Learning to live with early dementia. Can J Nurs Res. 2002;34:67-85.

53. Beard RL. In their voices: identity preservation and experiences of Alzheimer's disease. J Aging Stud. 2004;18:415-428.

54. Beard RL, Fox PJ. Resting social disenfranchisement: negotiating collective identities and everyday life with memory loss. Soc Sci Med. 2008;66:1509-1520.

55. Laakkonen ML, Raivio MM, Eloniemi-Sulkava U, Tilvis RS, Pitkala $\mathrm{KH}$. Disclosure of dementia diagnosis and the need for advance care planning in individuals with Alzheimer's disease (Letter to the Editor). $J$ Am Geriatr Soc. 2008;56(11):2156-2157.

56. Harman G, Clare L. Illness representations and lived experience in early-stage dementia. Qual Health Res. 2006;16(4):484-502.

57. Benbow SM, Ong YL, Black S, Garner J. Narratives in a user and carers' group: meanings and impact. Int Psychogeriatr. 2009;21:33-39.

58. Shaji KS, Smitha K, Lal KP, Prince MJ. Caregivers of people with Alzheimer's disease: a qualitative study from the Indian 10/66 Dementia Research Network. Int J Geriatr Psychiatry. 2003;18:1-6.

59. Keady J, Williams S, Hughes-Roberts J. Emancipatory practice development through life-story work: changing care in a memory clinic in North Wales. Pract Dev Health Care. 2005;4(4):203-212.

60. Banningh LJW, Vernooij-Dassen M, Rikkert MO, Teunisse JP. Mild cognitive impairment: coping with an uncertain label. Int $J$ Geriatr Psychiatry. 2008;23:148-154.

61. Manthorpe J, Samsi K, Campbell S, et al. The Transition from Cognitive Impairment to dementia: Older People's Experiences. Southampton: NIHR Service Development and Organisation Programme; 2011.

62. Langdon SA, Eagle A, Warner J. Making sense of dementia in the social world: a qualitative study. Soc Sci Med. 2007;64:989-1000.

63. Wolverson EL, Clarke C, Moniz-Cook E. Remaining hopeful in early stage dementia: a qualitative study. Aging Ment Health. 2010;14:450-460.

64. Abley C, Manthorpe J, Bond J, et al. Patients' and carers' views on what constitutes high quality communication and information when undergoing assessments in memory services. J Health Serv Res Policy. 2013;18(18):3.

65. Samsi K, Manthorpe J, Rapaport P. "As people get to know it more": experiences and expectations of the Mental Capacity Act 2005 amongst local information, advice and advocacy services. Soc Policy Soc. 2011;10(1):41-54. 
66. Dementia Roadmap [webpage on the Internet]. Available from: http:// dementiaroadmap.info. Accessed October 14, 2014.

67. Royal College of General Practitioners Press Office. A new route to good dementia care. [webpage on the Internet]. Available from: http://www. rcgp.org.uk/news/2014/may/a-new-route-to-good-dementia-care.aspx. Accessed July 25, 2014.
68. Tucker S, Wilberforce M, Brand C, Abendstern M, Challis D. All things to all people? The provision of outreach by Community Mental Health Teams for Older People in England: findings from a national survey. Int J Geriatr Psychiatry. 2014;29(5):489-496.

\section{Publish your work in this journal}

Clinical Interventions in Aging is an international, peer-reviewed journal focusing on evidence-based reports on the value or lack thereof of treatments intended to prevent or delay the onset of maladaptive correlates of aging in human beings. This journal is indexed on PubMed Central, MedLine,

\section{Dovepress}

CAS, Scopus and the Elsevier Bibliographic databases. The manuscript management system is completely online and includes a very quick and fair peer-review system, which is all easy to use. Visit http://www.dovepress. com/testimonials.php to read real quotes from published authors. 